\title{
A Novel Mutation in the Promoter Region of Avian Uncoupling Protein 3 Associated with Feed Efficiency and Body Composition Traits in Broiler Chicken
}

\author{
Mojtaba Darzi Niarami ${ }^{1}$, Ali Akbar Masoudi ${ }^{2}$, Rasoul Vaez Torshizi ${ }^{2}$ and Peymaneh Davoodi ${ }^{3}$ \\ ${ }^{1}$ Master degree of Animal Breeding, Tarbiat Modares University, Tehran, Iran \\ ${ }^{2}$ Association Professor at Department of Animal Science, Faculty of Agriculture, Tarbiat Modares University, Tehran Iran \\ ${ }^{3}$ PhD student of Animal Breeding and Genetic in Tarbiat Modares University, Tehran, Iran \\ *Corresponding author’s E-mail: Masoudia@modares.ac.ir; ORCID: 0000-0002-3935-0476
}

Received: 14 Jan. 2020

Accepted: 26 Feb. 2020

\begin{abstract}
The Avian Uncoupling Protein (avUCP) belongs to the mitochondrial anion transporter family. It has a pivotal homeostatic mechanism that associated with energy regulation and lipid metabolism. The avUCP considered as a candidate gene for chicken growth-related traits according to its predominant expression is in skeletal muscle. To address genetic distance pattern of UCP3 between mammalian and avian species, sequence similarity analysis using the protein alignment of UCP3 identified the high amino acid identity between the species and complementarily detected two protein conserved regions which are known as the ADP/ATP transporter translocase and the Mitochondria-carrier. Likewise, for mutation detection, samples were genotyped, afterward PCR-SSCP method implemented. In addition, association analysis was performed for investigating single nucleotide polymorphism within the UCP3 gene relating to the given economic traits. A detected polymorphic site, on the promoter region of UCP3 (-40 T/A substitution), has displayed significant influences on the Feed Conversion Rate (FCR), Residual Feed Intake (RFI), Average Daily Gain (ADG), and Carcass Weight (CW\%). In the case that, birds with genotype AA had better FCR, ADG, RFI as compared to the genotype BB and birds with genotype AA revealed a higher CW\% as compared to the genotype BB. According to the obtained results from the in-silico survey, Myoblast determination protein (MyoD) was predicted as a best-matched transcription factor with a consensus sequence harboring the -40 T/A -novel SNP- in the promoter region of UCP3, where might be responsible for phenotypic variation between two genotypes. In conclusion, the result suggests important roles for UCP3 polymorphism in feed efficiency and growth traits which is better to be used in broiler chicken breeding programs.
\end{abstract}

Key words: Association analysis, Avian uncoupling protein3, Body composition traits, Broiler chicken, Feed efficiency, Novel mutation

\section{INTRODUCTION}

Mitochondria are the primary site of cellular energy production, generating the most of the cell's supply of ATP by using the energy derived from the oxidation of nutrients to create an electrochemical gradient across the mitochondrial inner membrane through proton pumping from the matrix (Lodish et al., 2000; Kolath et al., 2006). Actually the electron transport chain is composed of 83 subunits, 70 of which are encoded by the nuclear and the rest 13 encoded by the mitochondrial genome (Lodish et al., 2000). The nuclear-encoded proteins (uncoupling proteins 2 and 3) can uncouple oxidative phosphorylation and electron transport by transporting protons back into the mitochondrial matrix due to increasing the permeability of the inner mitochondrial membrane (Garlid et al., 2000; Criscuolo et al., 2006; Jastroch et al., 2010). A Survey conducted by Raimbault et al, in 2001 has discovered a mitochondrial Uncoupling Protein (UCP) homolog in the avian lineage for the first time, which called as Avian Uncoupling Protein (avUCP), also they have been highlighted that avUCP is sharing more than $70 \%$ amino acid homology with both mammalian UCP2 and 3 (Raimbault et al., 2001). However, most of the recent attention has been devoted to the important contribution of UCPs to non-shivering thermogenesis, thyroid hormone control, and cold-induced gene expression (Raimbault et al., 2001; Masaaki et al., 2002; Pawade et al., 2005; Rey et al., 2010). Whereas, regulation of UCP3 expression appeared to be related with Free Fatty Acid (FFA) utilization and free radical metabolism (Jian-Guo et al., 2005; Murata et al., 2013; 
Moazeni et al., 2016). Therefore, avUCP can act as similar to mammalian UCPs, which have been strongly inducing during cold-exposure states (Raimbault et al., 2001; Masaaki et al., 2002; Rey et al., 2010; Nguyen et al., 2015; Lin et al., 2017).

Additionally, the vast investigation indicated that this protein may play a major role in body energy expenditure, particularly in skeletal muscle (Bailey et al., 1998; Boss et al., 1998; Raimbault et al., 2001; Abe et al., 2006; Liu et al., 2007). In addition, consecutive pieces of literature were implemented to characterize the gene structure and detect variants in the UCP3, paid particular attention to alteration in energy expenditure, growth, obesity, and body mass index in Human (Mutombo et al., 2013; Brondani et al., 2014; An et al., 2018). Also, UCP3 variation analysis in animal genetic fields, collectively, elucidated significant differentiation on feed efficiency and performance traits in farm animals (Choi et al., 2006; Kolath et al., 2006; Liu et al., 2007; Murata et al., 2013; Moazeni et al., 2016; Jin et al., 2018). Therefore, running lines of evidence which have justified the localized expression of avUCP in skeletal muscle in birds and its biological function of decreasing mitochondrial membrane potential and mediating proton leaks, made it a suitable candidate gene related to fat metabolism and production traits in the chicken (Masaaki et al., 2002; Abe et al., 2006; Rey et al., 2010; Murata et al., 2013).

As a result of any alteration in promoter regions that can change the activity of encoded protein so it will modify energy expenditure by affecting on the coupling level of oxidative phosphorylation, thereby providing variations in body weight and abdominal fat (Liu et al., 2007; Cieslak et al., 2009; Jastroch et al., 2010; Murata et al., 2013). Since, more accumulation of fat could decrease the feed conversion rate and meat quality in meat-typed chicken, therefore, rapid growth and lower fat deposition have required a great deal of interest concordantly in recent and following years because of its prominent issues in animal breeding (Sharma et al., 2008; An et al., 2018; Jin et al., 2018). In summary, due to a broad perspective appeared from previous studies, UCP3 has a crucial impact on growth traits and feed efficiency in many species. Besides, efficient genomic variations have been thought ordinarily of as a key factor for selection strategies, genetic improvement and ultimately having soared in the chicken meat industry, so the UCP3 can be a candidate gene for chicken production performance. Accordingly, the aim of the present study was to examine the association of a novel polymorphism in the promoter region of the UCP3 gene with feed efficiency and body composition traits in broiler chickens.

\section{MATERIAL AND METHODS}

\section{Phenotypic measurements}

The experiment carried out using Iranian commercial lines of Arian broiler chicken including two dam and sire lines. All lines primarily selected for growth traits in sire lines and reproductive traits in dam lines, for 19 successive generations and finally, a total of 253 day-old chickens selected at generation 19 to rear on the floor with ad libitum access to feed and water. The chicks fed on commercial corn-soybean diets in accordance with the national research council requirements containing 2745 $\mathrm{kcal} / \mathrm{kg}$ Metabolizable Energy (ME), $14.3 \%$ Crude Protein (CP) and $2920 \mathrm{kcal} / \mathrm{kg} \mathrm{ME}, 13.3 \% \mathrm{CP}$ respectively in dam and sire lines.

At the age of 21 days, all chicks weighed individually by digital scale, then transferred to the individual cages and grown for another 21 days recording for traits including Feed Conversion Ratio (FCR), Average Daily Gain (ADG), Residual Feed Intake (RFI), and Daily feed Intake (DFI) in all birds through 21 days as follows: The FCR calculated by dividing the mass of input (feed intake) by the mass of output (meat production) for measuring the efficiency of converting food into the desired output (Willems et al., 2013).

Next, the RFI also calculated as a difference between actual and predicted feed intakes based on body weight and growth rate. In the end, once the trial accomplished, the DFI calculated from offered and refused food by birds in each cage, then the ADG captured for the same period of rearing (Zhen-qiang et al., 2014). After fasting for 12 hours on 42th days, sample birds weighed individually, then, transferred to the slaughter-house and sacrificed by manual exsanguination using ethical guidelines according to animal welfare legislation, afterward, body composition traits such as Final Body Weight (FBW), Drumstick Weight (DW), Carcass Weight $(\mathrm{CW})$, Breast Muscle Weight (BMW), Abdominal Fat Weight (AFW), Hand Weight (HNDWT) and Back Weight (BAKWT) recorded by digital scale as well.

DNA sequencing, Polymorphism Chain ReactionSingle-strand conformation polymorphism and population screening for single-nucleotide polymorphisms

Required DNA extracted from whole blood using modified salting-out procedure (Miller et al., 1988). Four 
sets of primers (table 2) designed based on the sequence of UCP3 gene given from the GenBank database. Amplification of the UCP gene was performed in the volume of $20 \mu \mathrm{l}$ containing $100 \mathrm{ng}$ of genomic DNA, 1× PCR buffer, 1 unit of Taq DNA polymerase (Cinagene, Iran), $2.5 \mathrm{mM}$ dNTPs, $10 \rho$ mol of each primer and $2 \mathrm{mM}$ $\mathrm{MgCl}$ 2_PCR condition was set in three min initial denaturation at $94{ }^{\circ} \mathrm{C}, 35$ cycles of 45 s denaturing at $94{ }^{\circ} \mathrm{C}$, $45 \mathrm{~s}$ annealing at $62{ }^{\circ} \mathrm{C}$ and $45 \mathrm{~s}$ elongation at $72{ }^{\circ} \mathrm{C}$. Amplification product was assessed on a $1.5 \%$ agarose gel electrophoresis and purified using a QIAquick Gel extraction micro centrifuge and vacuum (QIAGEN, USA) according to the manufacturer's instructions. To increase the reliability of measures, direct sequencing was performed on both strands in samples of each line by applying the primer sets using the 3730XL DNA analyzer (Applied Biosystem (ABI), USA). Single Strand Conformation Polymorphism (SSCP) method was used to evaluate the frequency of the SNPs in the promoter region of the gene at the population level because it is a simple and sensitive technique for mutation, detection and genotyping (Hayashi 1992). The PCR pair primer of 5' GAG CGG GAT TTG ATT CTG TGC 3' and 5' GAA GGT GCA GAG GTC AGC GAT 3' was designed in both forward and reverse strands to amplify a 230-bp of UCP's promoter region harboring the substitution. The PCR condition was the same as the method mentioned above except adding 5\% Ddimethyl Sulfoxide (DMSO). Then, $10 \mu \mathrm{l}$ PCR product mixed with $8 \mu$ l loading buffer $(98 \%$ Formamide, 0.025\% Bromophenol blue, 0.025\% Xylene Cyanol, $10 \mathrm{mM}$ Ethylenediamine Tetraacetic Acid (EDTA). The mixture, then denatured at $95^{\circ} \mathrm{C}$ for five min, and placed in to an icebox for five min, and in the next stage, electrophoresed for 8 to $12 \mathrm{~h}$ at 200 Von a $6 \%$ polyacrylamide gel with $10 \%$ glycerol. The silver staining method implemented to visualize the DNA patterns on the gel. The samples producing different SSCP patterns on the gel, finally DNA segments sequenced to confirm the causative SNP.

\section{Statistical model and analysis method}

One of the most well-known statistical model for using in association analyses is GLM (Fang et al., 2009). So that the association between the UCP mutations with growth and body composition traits analyzed by GLM procedure (SAS, version 9.4). The fitted model contained fixed effects of genotype ( $\mathrm{G}$ with 2 levels), sex ( $\mathrm{S}$ with 2 levels), and line (L with 4 levels) and random effect of sire (SI) nested within the lines SI (L), as follows:

$$
y=\mu+G+S+L+S I(L)+e .
$$

where $\mathrm{y}$ is the response variable, $\mu$ is the population mean, and e is unknown random error. Significant differences between least square means of the different genotypes were calculated using a LSMEANS contrast procedure (Wang and Goonewardene, 2004). The significance threshold defined at $\mathrm{P}<0.05$ level.

Table 1. Four sets (the sets number 1 to 4 ) of designed primers used for sequencing the avian uncoupling protein gene in Arian bird samples and set 5 used for single-strand conformation polymorphism analysis

\begin{tabular}{|c|c|c|c|}
\hline تّँّ & 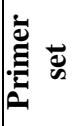 & Sequences of designed primer & 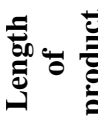 \\
\hline \multirow{10}{*}{ 己ֶ, } & \multirow{2}{*}{1} & F 5'-GAGCGGGATTTGATTCTGTGC-3' & \multirow{2}{*}{946} \\
\hline & & R 5'-GGTGGGTTGGTCCTTCATTGG-3' & \\
\hline & \multirow{2}{*}{2} & F 5'-TGGGACCAATCATGTCAGTGG-3' & \multirow{2}{*}{876} \\
\hline & & R 5'-ATGGATGGAGCTACGGACACC-3' & \\
\hline & \multirow[b]{2}{*}{3} & F 5'-GATAGTGGTGAGGAAGGTAGG-3' & \multirow{2}{*}{734} \\
\hline & & R 5'-AAAGCAGCCACGAAGTGACAG-3' & \\
\hline & \multirow{2}{*}{4} & F 5'-CATCAAAGGACACACTGCTGC-3' & \multirow{2}{*}{801} \\
\hline & & R 5'-AGGAATACCCGGACTCACCAC-3' & \\
\hline & \multirow[b]{2}{*}{5} & F 5'-GAGCGGGATTTGATTCTGTGC-3' & \multirow{2}{*}{230} \\
\hline & & R 5'-GAAGGTGCAGAGGTCAGCGAT-3' & \\
\hline
\end{tabular}

Primer sets designed in Tarbiat modares laboratory based on the sequence of UCP3 gene with accession number AF433170.2 from the GenBank, USD. UCP3: uncoupling protein3; F: forward; R: reverse

\section{Bioinformatics studies}

To address genetic similarity of UCP3 between mammalian and avian species, sequence similarity analysis used the protein alignment of UCP3. Moreover, Evolutionary relationship assessed by measuring pairwise distance between species, since several sources of molecular information have been undertaken to illustrate evolutionary relationships, protein sequences of chicken and 14 other species extracted from NCBI database. Then, phylogeny and molecular evolutionary analyses conducted by using MEGA in order that, genetic distances derived from protein weight matrix by using BLOSUM algorithm for homology searches (Tamura et al., 2011). Then phylogenetic tree drown using both character-based and distance-based procedure presented in maximum likelihood model. For the reason, achieving better interpretation, promoter and transcription factor prediction performed by different online software including EPD, BBCU and TFBIND (Matys et al., 2003; Deaton and Bird 2011; Gaudry and Campbell, 2017; Lizio etal., 2017). The TFBIND online software uses weight matrix in 
transcription factor (TF) database. Since this database uses all sequences related to TATA-Box, initiator region, CCAAT-Box, and GC-box it can obtain more purified and reliable results (Matys et al., 2003; Kumar et al., 2017).

\section{Ethical approval}

All bird's experiment performed according to standard animal welfare and approved by the Committee of Animal Science of Tarbiat Modares University, Iran. All experimental protocols applied in accordance with relevant legislation and recommendations by this committee.

\section{RESULTS}

\section{Sequence analysis, Single Nucleotide Polymorphism detection and genotyping}

The first set of analyses examined whether variation can be discovered in the interested gene or not. Direct sequencing of the UCP3 gene in sample birds discoverd five novel polymorphic sites including, a substitution of 40 T/A in 5' Untranslated Region (5' UTR), a silent mutation of $1833 \mathrm{~A} / \mathrm{G}$ in fourth exon, and also the rest of mutant-sites detected in third intron and 3' UTR, but We for further exanination just foucesd on a novel polymorphic site in promoter region or 5' UTR. Due to the importance of the mutations which occur in the promoter region of the genes, further analyses particularly conducted to examin -40 T/A polymorphic site. As figure showes, $-40 \mathrm{~T} / \mathrm{A}$ substitution produced two different SSCP pattern on gel, namely $A$ and $B$ across the population (Figure 1).

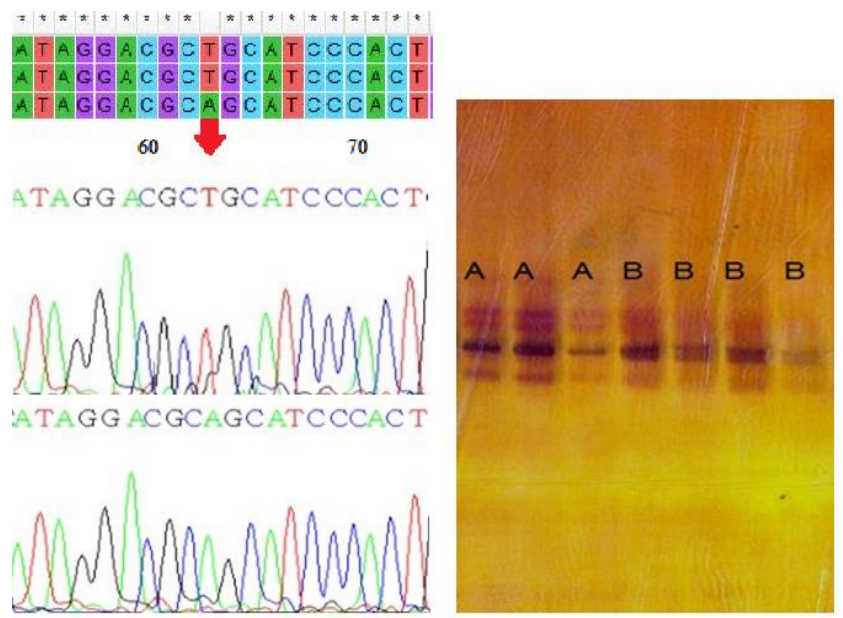

Figure 1. Electrograph of 230 base-pair sequenced segment of uncoupling protein3 gene carrying a novel single nucleotiede polymorphism in Arian lines
Association of avian uncoupling protein 3 -40 T/A polymorphism with feed efficiency and body composition traits

The genotypes of $-40 \mathrm{~T} / \mathrm{A}$ in upstream site of the UCP3 included in the genetic association analysis. HardyWeinberg Equilibrium test (HWE) for this locus indicated that this site is out of HWE. Because allelic frequency in this locus indicated that, allele A with a frequency of 0.67 was more prevalent than allele $B$ with frequency of 0.33 in the trail population. There were significant associations between this polymorphism and all feed efficiency traits including FCR, ADG and RFI $(\mathrm{P}=0.001)$ except DFI. So that chickens with genotype AA indicated better FCR and RFI than genotype $\mathrm{BB}$, and also chickens with genotype AA displayed higher ADG than genotype BB. Likewise, $40 \mathrm{~T} / \mathrm{A}$ substitution was significantly associated with carcass weight percentage of samples $(P=0.05)$ so that chickens with genotype AA revealed a higher $\mathrm{CW} \%$ than the birds with genotype BB. However, tiny differences in other composition traits (CW, DW, BMV, AFW and AFW $\%$ ) did not show any association (Table 2).

Table 2. Least square means \pm SE for feed efficiency and body composition traits among genotypes in the uncoupling protein 3 in broiler chickens considering the effects of $-40 \mathrm{~T} / \mathrm{A}$ substitution

\begin{tabular}{lccc}
\hline \multirow{2}{*}{ Trait } & \multicolumn{2}{c}{ Genotype } & \multirow{2}{*}{ P-value } \\
\cline { 2 - 3 } & AA & BB & \\
\hline FCR g:g & $1.925 \pm 0.023$ & $2.149 \pm 0.04$ & $0.000^{* * *}$ \\
RFI (g) & $1.421 \pm 0.006$ & $8.854 \pm 2.62$ & $0.017^{* *}$ \\
DFI (g) & $165.8 \pm 1.951$ & $164.8 \pm 3.462$ & 0.827 \\
ADG (g/d) & $86.298 \pm 0.898$ & $77.485 \pm 1.593$ & $0.000^{* * *}$ \\
CW (g) & $1661.9 \pm 10.987$ & $1626 \pm 26.692$ & 0.513 \\
DW (g) & $473.99 \pm 5.43$ & $473.62 \pm 8.883$ & 0.674 \\
BMW (g) & $550.14 \pm 3.286$ & $533.45 \pm 9.628$ & 0.236 \\
AFW(g) & $22.616 \pm 0.862$ & $26.625 \pm 1.544$ & 0.113 \\
CW\% & $69.157 \pm 0.337$ & $66.834 \pm 0.934$ & $0.053^{*}$ \\
AFW\% & $0.911 \pm 0.037$ & $1.08 \pm 0.62$ & 0.111 \\
\hline SE:
\end{tabular}

SE: standard error; FCR: feed conversion ratio in the interval; RFI: residual feed intake from 21 to 42 days of age; DFI: daily feed intake; ADG: average daily gain; CW: carcass weight; DW: drumstick weight; BMV: breast muscle weight; AFW: abdominal fat weight

\section{Bioinformatics' results}

In this study promoter prediction performed by TFBIND and the logical results presented in table.3. The predicted binding sites and transcription factors including: Myoblast determination protein (MyoD with M00184 code), Specificity Protein 1 (SP1 with M00008 code), and Nuclear factor I (NF1 with M00193 code) corresponded to 
the consensus sequences of promoter region of UCP3. Amazingly, MyoD was exactly covering the region harboring novel single nucleotide polymorphism. The Schematic figure of matched transcription factor with binding sites in promoter region of uncoupling protein gene has designed in figure 3 . To address genetic distance pattern of UCP3 between mammalian and avian species, alignment of protein sequences in UCP3s identified high amino acid identity between the species and complementarily detected two protein conserved regions which are known as the ADP/ATP transporter translocase and the Mitochondria-carrier. The output of genetic distance and revolution relationship between mentioned species displayed in a figure of rooted phylogenetic tree using maximum likelihood method that indicates common ancestor of UCP3 in all species (Figure 4).

Table 3. Predicted transcription factors and binding sites in promoter region of uncoupling protein 3 gene of broiler chicken by TFBIND online software

\begin{tabular}{llll}
\hline Code & Transcription factors & Score & Consensus sequence of binding sites \\
\hline M00008 & SP1 & 0.823046 & GRGGCRGGGWGTTCCCCCCC \\
M00184 & Myo D & 0.781616 & NNCANCTGNYTCCCACTGCC \\
M00193 & NF1 & 0.741892 & NNTTGGCNNNNNNCCNNNTCTATCCGTGAGCCAGGA \\
\hline
\end{tabular}

SP1: Specificity Protein 1; Myo D: Myoblast determination protein; NF1: Nuclear factor I

Upstream region of UCP3 ( Promoter of UCP3)

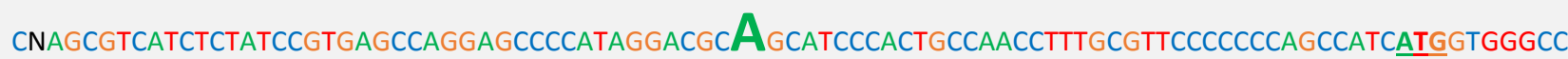

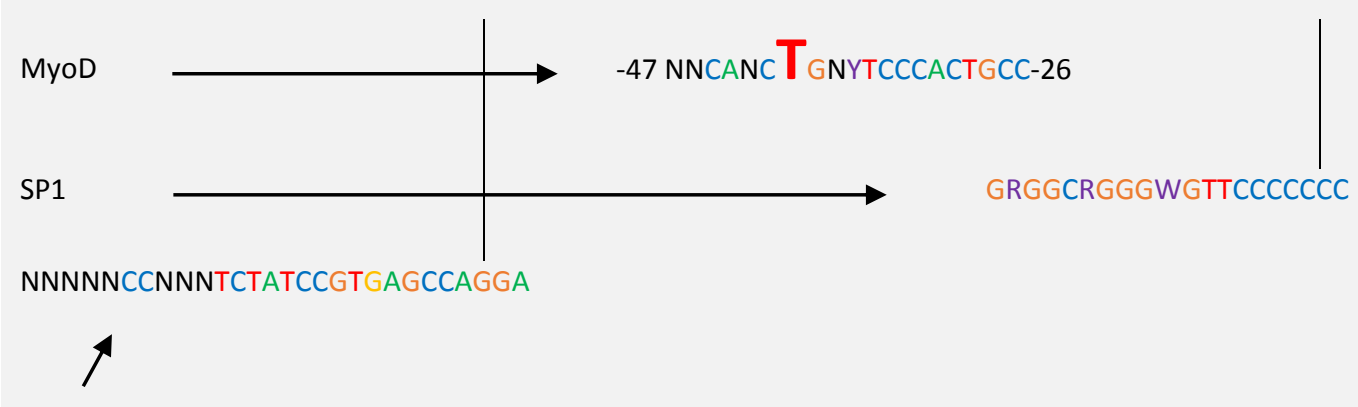

NF1

Figure 3. Schematic figure of predicted binding sites in uncoupling protein gene by MyoD with the logo of MyoD in Bioinformatics analysis. UCP3: Uncoupling protein3; SP1: Specificity Protein 1; Myo D: Myoblast determination protein; NF1: Nuclear factor I

\section{DISCUSSION}

The candidate gene approach has been known as a significant tool to improve the selection methods by finding behind the curtain association between genotype variation in certain gene and phenotype of interest (Liu et al., 2007; Moazeni et al., 2016; Jin et al., 2018). Thus, by discovering the contribution of UCP3 in the regulation of energy metabolism, it is concluded that it may affect the production traits and promote the performance of meattype poultry. As a consequence, the polymorphism of UCP3 can be used in genetic improvement if genotypic and allelic frequencies are determined. Since the confirmation of such effects requires a considerable amount of multilateral studies, and there is still insufficient information on the function of this gene, so, to pave the path for finding this information, this study was designed.

A basic objective of our research was to estimate the allelic and genotypic frequency of UCP3 polymorphism of the $-40 \mathrm{~T} / \mathrm{A}$ substitution in the promoter region in distinct genotypes. Hardy-Weinberg Equilibrium test (HWE) can be used for searching how the alleles within one locus are in equilibrium, this test for polymorphic locus in upstream of UCP3 in our samples indicated that it is out of HWE, because certain selection strategies for reproduction and production traits in both dam and sire lines of Arian chickens affected the allelic frequencies during the past years Arian population. 
To detect the association of UCP3 variants, according to the result of frequency association analyses that presented in table 3, the pattern of genotype AA showed maximum frequency $(0.7312 \%)$ and the pattern of genotype BB indicated minimum frequency $(0.2688 \%)$. Moreover, genotype AA produced better performance for most of feed efficiency traits except DFI than genotype BB. Although there were no significant differences between the two genotypic patterns in body composition traits, except CW\% ( $<<0.053$ ), that figured out chickens with AA genotype had higher CW\% compared to chickens with $\mathrm{BB}$ genotype pattern. On average, body composition traits in chickens with genotype AA were superior to those with BB genotype. Also, Sharma et al. in 2008 suggested that polymorphism in the avUCP is associated with feed conversion and body weight in commercial broiler lines which approves our findings in the present study (Sharma et al., 2008).

Moreover, in the human field, some supportive investigations have indicated common mutations on promoter sites of UCP3 are associated with childhood obesity, energy expenditure, body weight alteration, and BMI (Mutombo et al., 2013; Brondani et al., 2014).

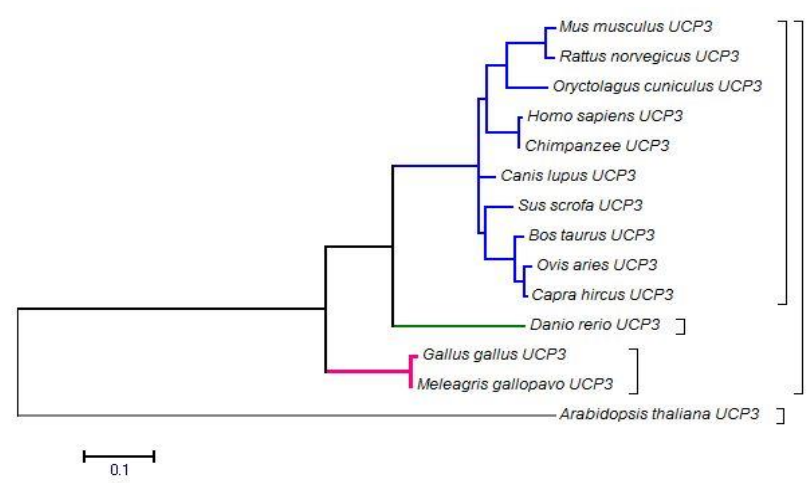

Figure 4. Molecular Phylogenetic analysis of the uncoupling protein 3 in 14 different species by using protein sequences

Almost every research conducted on UCP3 recommended some promotion in feed efficiency and growth performance traits in chicken associated with UCP3 polymorphism in chicken (Nguyen et al., 2015; Moazeni et al., 2016; Jin et al., 2018), in Japanese quail (Murata et al., 2013), in New Zealand Romney lambs (An et al., 2018), and in Angus' steers (Kolath et al., 2006). Furthermore, recent studies suggest that proton uncoupling action of UCP3 in mitochondria can permit heat production and regulate energy metabolism in beige adipose tissue in pigs (Cieslak et al., 2009; Lin et al., 2017).

As usual, the less abdominal fat in chickens enhances the quality and market acceptability of meat production. In addition, emerging evidence report that lipid metabolism to be controlled by UCP3, and it has been found to be associated with fat distribution and accumulation of abdominal fat in avian species (Liu et al., 2007; Murata et al., 2013). Conversely, the data structure in our research did not reveal a significant influence on abdominal fat weight between different genotypes carrying the novel SNP. This contrasting result may come from the fact that different determinants including hormonal levels, nutrition, genotypes, and even data structure are responsible for phenotypic plasticity (DeJong and Bijma 2002; Johnsson et al., 2018). The strategy of using UCP3 polymorphism as a DNA marker would increase body weight, improve production quality and decrease abdominal fat next will cause low production costs in the poultry industry (Liu et al., 2007; Moazeni et al., 2016; An et al., 2018; Jin et al., 2018). The existence of some alteration in the promoter region makes biological sense which confirms regulatory sequences should be variable. Since gene promoters are critical role players in gene regulation, so they ordinarily receive signals from different sources to down and up-regulate the level of transcription, which mainly determines gene expression (Rey et al., 2010; Hoffmann et al., 2013; Murata et al., 2013). For the reason, that transcription start sites and surrounding regulatory elements normally are often in the upstream region of gene sequence. Therefore, we deduced that if the novel change occurs in the allelic level by substitution of $\mathrm{T}$ to $\mathrm{A}$ in promoter region finally will cause significant variation in phenotype in birds which are harboring different types of variants. On the other hand, the UCP3 has been shown to involve in the regulation of some biological process of energy metabolism so it is most likely to have an effect on pathways related to growth performance (An et al., 2018; Jin et al., 2018).

On the other side, due to the sequence identity, mitochondrial proteins were grouped into the core UCP family and phylogenetic deduction classifies avUCP as a UCPs orthologue (Jastroch et al., 2010; Tamura et al., 2011; Pardi and Gascuel, 2016). Besides, it should be considered that relatively little information is available concerning regulatory mechanisms of UCP in avian species, especially about promoter binding sites and other controlling elements (Jian-Guo et al., 2005; Lizio et al., 2017). Notwithstanding the fact that existing some differences in the number of exons and the genomic region 
that the gene is located on, our assessment in the field of sequence alignment of UCP3 from chicken and other species has demonstrated a relatively uniform structure that displays conserved composition of amino acids in UCP3 between studied species which means UCP3 is under purifying natural selection, suggesting that it's functions has not changed severely during evolution. The amino acid similarity above $70 \%$ previously endorsed by Raimbault et al. (2001). The conserved regions in uncoupling protein encoded by UCP3s in different species, known as the ADP/ATP transporter translocase and the Mito_carr with slight variation in the state of their genomic region (Gaudry and Campbell, 2017; Lin et al., 2017).

In the current study, -40 T/A SNP in UCP3 located in promoter region, and since a possible explanation for this might be that the promoter is the most important region to gene transcription, because, in initial stage of gene transcription, specific transcriptional factors should bind to the promoter site, so any mutations or indels, particularly in binding sites can alter the pattern of transcription and finally change the phenotype ( $\mathrm{Lu}$ and Sack, 2008; Deaton and Bird 2011; De-Luis et al., 2012).

Bioinformatics available tools have provided the opportunity to predict certain parameters based on the genomic information of other organisms. In this regard, we used in silico analyses for prediction of probable binding sites in the promoter region and transcription factors, using the humane and mouse genomic information. The output of prediction represents that -40 T/A located in the probable consensus binding motifs in the promoter region and might combine with MyoD which qualified in this study. (Bailey et al., 1998; Solanes et al., 2000; Hoffmann et al., 2013). If this hypothesis becomes true so the significant changes in the mentioned traits will become more justified. According to text mining further transcription factors have been found related to UCP3 such as Coup-TFII, MyoD, Sp1, PPAR-alpha, and the others (Lu and Sack, 2008; Hoffmann et al., 2013). As biology is mysterious and complicated we guess other regulators have been located out of our eyes. To support this attitude, we point to study which determined that the product of UCP3 can be governed by a complex interaction between chicken ovalbumin upstream promoter transcription factor II (Coup-TFII) and other transcription factors including PPARalpha, MyoD, and histone acetyltransferase p300.

Bailey et al. (1998) and Solanes et al. (2000) already underlined that when MyoD as a promoter activator of UCP3, co-transfects, then other factors will contribute and can cause a significant induction. Additionally, extra findings obtained from previous studies have established that any alteration in the promoter region and binding sites can counteract the attachment of MyoD, PPAR, and other transcription factors so that ultimately transcription level can be attenuated ( $\mathrm{Lu}$ and Sack, 2008; Nguyen et al., 2015).

As this novel SNP is located exactly in the predicted consensus region mentioned in table 3 . It can be concluded it was able to alter the transcription level. Finally, it is deduced that excavated association between UCP3's SNP and phenotypes in broiler lines most likely produced by underlying linkage disequilibrium between this SNP and causal gene which modulates the expression of the UCP3 in our chicken samples. Although, it should be noted the significant associations obtained in this study needs to be confirmed by increasing the sample size in further complementary studies and it might be a distinct application of this novel SNP which could be benefitted by further studies.

\section{CONCLUSION}

This study investigated the association between the sequence variant in the avUCP with feed efficiency and body composition traits in Arian broiler lines. The result identified new mutations in the structure of the gene. Association analysis indicated that a mutation in the promoter region was significantly associated with feed efficiency traits and carcass weight $\%$ in Arian broiler lines. Indeed, because of the location of the mutation in the promoter region and the vicinity of the mutation with some important transcription factors, in particular, MyoD, indicate that $-40 \mathrm{~T} / \mathrm{A}$ will be a valuable SNP for application in poultry breeding strategies by complementary study supports.

\section{DECLARATIONS}

\section{Acknowledgments}

We would like thank all colleagues in Arian commercial line center for their unlimited collaboration on animal dissection and sampling. This work was supported by a research grant of Tarbiat Modares University No. 821162.

\section{Authors' contributions}

Ali Akbar Masoudi designed the experiments and guided the team until the end, after all, edited and approved the final manuscript. Rasoul Vaez Torshizi 
performed statistical analysis and revised the manuscript. Mojtaba Darzi Niamami performed laboratory experiments and analyzed obtained data. Peymaneh Davoodi conducted bioinformatics analysis, writing and drafting manuscript. Finally, all authors read and approved the final manuscript and they consent to be published on JWPR.

\section{Competition interests}

The authors have declared that they have no competing interests

\section{REFERENCES}

Abe T, Mujahid A, Sato K, Akiba Y and Toyomizu M (2006). Possible role of avian uncoupling protein in down-regulating mitochondrial superoxide production in skeletal muscle of fasted chickens. Federation of European Biochemical Societies Letters. 580: 48154822. DOI:https://doi.org/10.1016/j.febslet.2006.07.070

An Q, Zhou H, Hu J, Luo Y and Hickford JGH (2018). Sequence and haplotypes variation of the ovine uncoupling protein-1 gene (ucp1) and their association with growth and carcass traits in new zealand romney lambs. Genes. 9: 189-201. DOI:https://doi.org/10.3390/genes9040189

Azzu V, Jastroch M, Divakaruni AS, and Brand MD (2010). The regulation and turnover of mitochondrial uncoupling proteins. Biochimica et Biophysica Acta. 1797: 785-791. DOI:https://doi.org/10.1016/j.bbabio.2010.02.035

Bailey P, Sartorelli V, Hamamori Y and Muscat GE (1998). The orphan nuclear receptor, coup-tf ii, inhibits myogenesis by posttranscriptional regulation of myod function: Coup-tf ii directly interacts with p300 and myod. Nucleic Acids Research. 26: 55015510. DOI:https://doi.org/10.1093/nar/26.23.5501

Boss O, Samec S, Kuhne F, Bijlenga P, Assimacopoulos JF, Seydoux J, Giacobino JP et al (1998). Uncoupling protein-3 expression in rodent skeletal muscle is modulated by food intake but not by changes in environmental temperature. Journal of Biological Chemistry. 273: 5-8. https://doi.org/10.1074/jbc.273.1.5

Brondani LA, Assmann TS, De-Souza BM, Bouças AP, Canani LH and Crispim D (2014). Meta-analysis reveals the association of common variants in the uncoupling protein (ucp) 1-3 genes with body mass index variability. PLOS ONE. 9: 96411-96421 DOI:https://doi.org/10.1371/journal.pone.0096411

Choi CH, Cho BW, Jeon GJ and Lee HK (2006). Identification of novel snps with effect on economic traits in uncoupling protein gene of korean native chicken. Asian-Australian Journal of Animal Science. 19: 1065-1070. DOI:https://doi.org/10.5713/ajas.2006.1065

Cieslak J, Nowacka-Woszuk J, Bartz M, Fijak-Nowak H, Grzes M, Szydlowski M and Switonski M (2009). Association studies on the porcine retn, ucp1, ucp3 and adrb3 genes polymorphism with fatness traits. Meat Science. 83: 551-554. DOI:https://doi.org/10.1016/j.meatsci.2009.07.001

De-Jong G and Bijma P (2002). Selection and phenotypic plasticity in evolutionary biology and animal breeding. Livestock Production Science. $\quad 78$ : 195-214. DOI:https://doi.org/10.1016/S0301$\underline{\text { 6226(02)00096-9 }}$

De-Luis DA, Aller R, Izaola O, Gonzalez-Sagrado $\mathrm{M}$ and Conde $\mathrm{R}$ (2012). Association of $-55 \mathrm{c} / \mathrm{t}$ polymorphism of ucp3 gene with fat distribution, cardiovascular risk factors and adipocytokines in patients with type 2 diabetes mellitus. Journal of Endocrinology Investigation. 35: 625-633. DOI:https://doi.org/10.3275/7908

Deaton AM and Bird A (2011). Cpg islands and the regulation of transcription. Genes and Developments. 25: 1010-1022. DOI:https://doi.org/10.1101/gad.2037511

Fang M, Nie Q, Luo C, Zhang D and Zhang X (2009). Associations of ghsr gene polymorphisms with chicken growth and carcass traits. Molecular Biology Reports. 37: 423-428 DOI:https://doi.org/10.1080/10495398.2013.803478

Garlid KD, Jaburek M, Jezek P and Varecha M (2000). How do uncoupling proteins uncouple? Biochimica et Biophysica Acta. 1459: 383-389. DOI:https://doi.org/10.1016/s0005-2728(00)00175$\underline{4}$

Gaudry MJ and Campbell KL (2017). Evolution of ucp1 transcriptional regulatory elements across the mammalian phylogeny. Frontiers in physiology. 8: 670-692. DOI:https://doi.org/10.3389/fphys.2017.00670

Hayashi K (1992). Pcr-sscp: A method for detection of mutations. Genetic, Analysis, Techniques and Applications. 9: 73-79. DOI:https://doi.org/10.1016/1050-3862(92).90001-I

Hoffmann C, Zimmermann A, Hinney A, Volckmar AL, Jarrett HW, Fromme T and Klingenspor M (2013). A novel sp1/sp3 dependent intronic enhancer governing transcription of the ucp3 gene in brown adipocytes. PLOS ONE. 8: e83426-e83426. DOI:https://doi.org/10.1371/journal.pone.0083426

Jian-Guo Z, Hui L, Yu-Xiang W and He M (2005). The expression characterization of chicken uncoupling protein gene. AsianAustralas Journal of Animal Science. 18: 1552-1556. DOI:https://doi.org/10.5713/ajas.2005.1552

Jin S, Yang L, He T, Fan X, Wang Y, Ge K and Geng Z (2018). Polymorphisms in the uncoupling protein 3 gene and their associations with feed efficiency in chickens. Asian-Australian Journal of Animal Science. 31: 1401-1406. DOI:https://doi.org/10.5713/ajas.18.0217

Johnsson M, Henriksen R, Höglund A, Fogelholm J, Jensen P and Wright D (2018). Genetical genomics of growth in a chicken model. BioMed Central Genetics. 19: 72-84. DOI:https://doi.org/10.1186/s12864-018-4441-3

Kolath WH, Kerley MS, Golden JW and Keisler DH (2006). The relationship between mitochondrial function and residual feed intake in angus steers. Journal of Animal Science. 84: 861-865. DOI:https://doi.org/10.2527/2006.844861x\%J

Kumar S, Ambrosini G and Bucher P (2017). Snp2tfbs - a database of regulatory snps affecting predicted transcription factor binding site affinity. Nucleic Acids Research. 45: 39-44. DOI:https://doi.org/10.1093/nar/gkw1064

Ledesma A, De-Lacoba MG and Rial E (2002). The mitochondrial uncoupling proteins. Genome biology. 3: 3015-3024. DOI:https://doi.org/10.1186/gb-2002-3-12-reviews3015

Lin J, Cao C, Tao C, Ye R, Dong M, Zheng Q, Wang C et al (2017). Cold adaptation in pigs depends on ucp3 in beige adipocytes. Journal of Molecular and Cellular Biology. 9: 364-375. DOI:https://doi.org/10.1093/jmcb/mjx018

Liu S, Wang SZ, Li ZH and $\mathrm{Li} \mathrm{H}$ (2007). Association of single nucleotide polymorphism of chicken uncoupling protein gene with muscle and fatness traits. Journal of Animal Breeding Genetics. 124: 230-235. $\quad$ DOI:https://doi.org/10.1111/j.14390388.2007.00654.x

Lizio M, Deviatiiarov R, Nagai H, Galan L, Arner E, Itoh M, Lassmann $\mathrm{T}$ et al (2017). Systematic analysis of transcription start sites in 
avian development. PLOS Biology. 15: 2002887-2002910. https://doi.org/10.1371/journal.pbio.2002887

Lu Z and Sack MN (2008). Atf-1 is a hypoxia-responsive transcriptional activator of skeletal muscle mitochondrial-uncoupling protein 3 . Journal of Biological Chemistry. 283: 23410-23418. DOI:https://doi.org/10.1074/jbc.M801236200

Masaaki T, Masatoshi U, Shinichi S, Yoshinori S, Kan S and Yukio A (2002). Cold-induced mitochondrial uncoupling and expression of chicken ucp and ant mrna in chicken skeletal muscle. Federation of European Biochemical Societies Letters. 529: 313-318. DOI:https://doi.org/10.1016/S0014-5793(02)03395-1

Matys V, Fricke E, Geffers R, Gossling E, Haubrock M, Hehl R, Hornischer $\mathrm{K}$ et al (2003). Transfac: Transcriptional regulation, from patterns to profiles. Nucleic Acids Research. 31: 374-378. DOI:https://doi.org/10.1093/nar/gkg108

Miller SA, Dykes DD and Polesky HF (1988). A simple salting out procedure for extracting DNA from human nucleated cells. Nucleic Acids $\quad$ Research. 16: 1215-1215. DOI:https://doi.org/10.1093/nar/16.3.1215

Moazeni SM, Mohammadabadi M, Sadeghi M, Moradi-Shahrbabak H, Esmailizadeh-Koshkoieh A and Bordbar F (2016). Association between ucp gene polymorphisms and growth, breeding value of growth and reproductive traits in mazandaran indigenous chicken. Open Journal of Animal Sciences. 6: 1-8 DOI:https://doi.org/10.4236/ojas.2016.61001

Murata S, Kawabe K, Taura S, Shimogiri T and Okamoto S (2013). Relationship between abdominal fat content and avian uncoupling protein gene expression in skeletal muscle of japanese quail coturnix japonica. British Poultry Science. 54: 42-51. DOI:https://doi.org/10.1080/00071668.2013.764398

Mutombo PB, Yamasaki M and Shiwaku K (2013). Ucp2 i/d modulated change in bmi during a lifestyle modification intervention study in japanese subjects. Genetic Test of Molecular Biomarkers. 17: 1620. DOI:https://doi.org/10.1089/gtmb.2012.0229

Myers SA, Wang SC and Muscat GE (2006). The chicken ovalbumin upstream promoter-transcription factors modulate genes and pathways involved in skeletal muscle cell metabolism. Journal of Biological Chemistry. 281: 24149-24160. DOI:https://doi.org/10.1074/jbc.M601941200

Nguyen P, Greene E, Ishola P, Huff G, Donoghue A, Bottje W and Dridi $S$ (2015). Chronic mild cold conditioning modulates the expression of hypothalamic neuropeptide and intermediary metabolic-related genes and improves growth performances in young chicks. PLOS ONE. 10 : 142319-142341 DOI:https://doi.org/10.1371/journal.pone.0142319

Pardi F and Gascuel O (2016). Distance-based methods in phylogenetics. Encyclopedia of Evolutionary Biology. 1: 458-465. Available at:https://hal-lirmm.ccsd.cnrs.fr/lirmm-01386569

Pawade T, Ho PW, Kwok KH, Chu AC, Ho SL and Ramsden DB (2005). Uncoupling proteins: Targets of endocrine disruptors? Mol Cell
Endocrinol.

244:

$79-86$ DOI:https://doi.org/10.1016/i.mce.2005.06.008

Raimbault S, Dridi S, Denjean F, Lachuer J, Couplan E, Bouillaud F, Bordas A et al (2001). An uncoupling protein homologue putatively involved in facultative muscle thermogenesis in birds. Biochemistry Journal. 353: 441-444. DOI:https://doi.org/10.1042/0264 6021:3530441

Rey B, Roussel D, Romestaing C, Belouze M, Rouanet JL, Desplanches D, Sibille B et al (2010). Up-regulation of avian uncoupling protein in cold-acclimated and hyperthyroid ducklings prevents reactive oxygen species production by skeletal muscle mitochondria. BioMed Central Physiology. 10: 1186-1191. DOI:https://doi.org/10.1186/1472-6793-10-5

Sharma P, Bottje W, and Okimoto R (2008). Polymorphisms in uncoupling protein, melanocortin 3 receptor, melanocortin 4 receptor, and pro-opiomelanocortin genes and association with production traits in a commercial broiler line. Poultry Science. 87: 2073-2086. DOI:https://doi.org/10.3382/ps.2008-00060

Solanes G, Pedraza N, Iglesias R, Giralt M, and Villarroya F (2000). The human uncoupling protein-3 gene promoter requires myod and is induced by retinoic acid in muscle cells. Federation of American Societies for Experimental Biology Journal. 14: 2141-2143. DOI:https://doi.org/10.1096/fj.00-0363fje

Tamura K, Peterson D, Peterson N, Stecher G, Nei M and Kumar S (2011). Mega5: Molecular evolutionary genetics analysis using maximum likelihood, evolutionary distance, and maximum parsimony methods. Molecular Biology Evolution. 28: 2731-2739. DOI:https://doi.org/10.1093/molbev/msr121

Tompa M, Li N, Bailey TL, Church GM, De-Moor B, Eskin E, Favorov $\mathrm{AV}$ et al (2005). Assessing computational tools for the discovery of transcription factor binding sites. Nature Biotechnology. 23: 137144. DOI:https://doi.org/10.1038/nbt1053

Villarroya F, Iglesias R and Giralt M (2007). Ppars in the control of uncoupling proteins gene expression. Peroxisome ProliferatorActivated Receptors (PPAR) Research 20: 74364-74386. DOI:https://doi.org/10.1155/2007/74364

Wang LA and Goonewardene Z (2004). The use of mixed models in the analysis of animal experiments with repeated measures data. Canadian Journal of Animal Science. 84: 1-11. DOI:https://doi.org/10.4141/A03-123

Willems OW, Miller SP and Wood BJ (2013). Aspects of selection for feed efficiency in meat producing poultry. World's Poultry Science Journal. 69: 77-88. DOI:https://10.1017/S004393391300007X

Zhen-qiang Z, Jie C, Yan Z, Cong-liang J, De-xiang Z and Xi-quan Z (2014). Determination of residual feed intake and its associations with single nucleotide polymorphism in chickens. Journal of Integrative $\quad$ Agriculture. 13: 148-157. DOI:https://doi.org/10.1016/S2095-3119(13)60383-4 